\title{
Proliferación de células madres mesenquimales obtenidas de tejido gingival humano sobre una matriz de quitosano: estudio in vitro
}

\author{
Proliferation of mesenchymal stem cells from human gingival tissue on chitosan \\ scaffold: an in vitro study
}

Hernández B M ${ }^{1}$, Inostroza V C ${ }^{2}$, Carrión A F ${ }^{3}$, Chaparro P A ${ }^{4}$, Quintero H A², Sanz R A²

\begin{abstract}
RESUMEN
Objetivo: Comprobar la proliferación de células madres mesenquimales (MSCs) provenientes de tejido conjuntivo gingival humano sobre una matriz de quitosano. Método: Estudio experimental in vitro en el cual se aislaron MSCs a partir de cultivos por explante de tejido conjuntivo gingival. La presencia de MSCs, se caracterizó mediante citometría de flujo, utilizando para ello anticuerpos CD34, CD45, CD73, CD90, CD105, diferenciación hacia tres linajes celulares: adipocitos, osteoblastos y condroblastos. La diferenciación fue corroborada mediante microscopía óptica con tinciones Oil Red, Alizarin Red y Safranina O respectivamente. La matriz de quitosano fue analizada mediante microscopía óptica. Las MSCs en pasaje 5, fueron sembradas en presencia de la matriz de quitosano. La proliferación de las células madres fue analizada mediante microscopía óptica y tinción con cristal violeta. Resultados: A partir del explante de tejido gingival humano se obtuvieron MSCs, que cumplieron con los criterios de caracterización morfológica y fenotípica correspondiente a una MSC. Las MSC adoptaron una morfología fibroblastoide, adherencia al plástico, confluencia de un $80 \%$ y sobre un $90 \%$ expresaron los marcadores CD73, CD90 y CD105 y bajo un 10\% fueron negativas para CD34, y CD45 por técnica de citometria de flujo. Las MSC cultivadas en presencia de quitosano proliferan, sin embargo observamos que a mayor concentración de quitosano en el cultivo disminuye la proliferación y densidad celular. La matriz de quitosano en presencia del medio de cultivo pierde sus propiedades físicas, disolviéndose y formando un gel no transportable. Conclusiones: A pesar de existir proliferación celular de MSCs de origen gingival humano en presencia de la matriz de quitosano, su utilidad como andamiaje y medio de transporte de MSC es deficiente debido a que se alteran sus propiedades físicas, disolviéndose y formando un gel no transportable en contacto con el medio de cultivo.
\end{abstract}

Rev. Clin. Periodoncia Implantol. Rehabil. Oral Vol. 4(2); 59-63, 2011.

Palabras clave: Células madres mesenquimales, regeneración periodontal, tejido gingival, quitosano.

\section{ABSTRACT}

Aim: The purpose of this study was to assess the proliferation of mesenchymal stem cells (MSCs) from human gingival tissue on chitosan matrix. Methods: Experimental study in vitro. Gingival connective tissue samples were obtained from healthy volunteers from the maxillary tuberosity. The explants were minced and cultured on tissue culture dishes. MSC were characterized by flow cytometry using markers for CD34, CD45, CD73, CD90, CD105 and for differentiation into, adipogenic, osteogenic and chondrogenic lineages. The tissue differentiated was analyzed with light microscopy and evaluated by culture staining using Oil Red, Alizarin Red y Safranina O respectively. MSC from passage 5 were cultured with chitosan scaffold. Proliferation of MSC was analyzed with light microscopy and crystal violet staining. Results: MSCs were obtained from gingival explants, and developed the standard of the morphologic and phenotypic characterization as a stem cell. The MSC adopted a fibroblastoid morphology, adherence to plastic, confluence of $80 \%$ and over $90 \%$ were consistently positive for CD90, CD105, CD73 markers and under $10 \%$ were negative for hematopoietic markers CD34 and CD45 by flow cytometry analysis. The MSC cultured in presence of chitosan matrix proliferated, however complete medium, it was dissolved forming a gel structure. We also observed that at higher concentrations of chitosan, MSC has less density and growth. Chitosan matrix in presence of cell culture medium loses physical properties, dissolving and forming a non-transportable gel. Conclusions: Despite the existence of proliferation of MSCs from human gingival tissue with chitosan matrix, its ability to act as a cell carrier and scaffold is deficient, since its physical properties are altered, dissolving and forming a non-transportable gel in contact with cell culture medium.

Rev. Clin. Periodoncia Implantol. Rehabil. Oral Vol. 4(2); 59-63, 2011.

Key words: Mesenchymal stem cells, periodontal regeneration, gingival tissue and chitosan.

\section{INTRODUCCIÓN}

La enfermedad periodontal es una enfermedad inflamatoria multifactorial que afecta los tejidos de protección y soporte del diente(1). La periodontitis, se caracteriza por la pérdida irreversible del tejido de inserción y óseo que dan soporte a las piezas dentarias y pueden causar su pérdida, la cual muchas veces genera un defecto óseo remanente que impide la rehabilitación mediante la instalación de implantes de titanio oseointegrados. Es así, como la recuperación del tejido óseo perdido, representa un gran desafío para la profesión odontológica. En la actualidad, la mayoría de los tratamientos se basan en el uso de injertos biocompatibles. El trasplante de hueso autólogo es el injerto de elección y se considera el "gold standard" debido a su excelente tasa de éxito, ya que presentan la habilidad de estimular la nueva formación ósea mediante el reclutamiento de células madres mesenquimales (MSCs) del huésped presentes en el periostio(2), teniendo así gran histocompatibilidad y bajo riesgo de transmisión de enfermedades. Sin embargo presenta limitada biodisponibilidad y su utilización aumenta la morbilidad del sitio donante(3). Es por esto que se ha recurrido al uso de injertos alogénicos, los cuales derivan de otro individuo de la misma especie, permitiendo reconstruir grandes defectos. El problema que presenta el uso de estos trasplantes es que existe la posibilidad de transmisión de enfermedades,

1. Cirujano Dentista. Facultad de Odontología, Universidad de los Andes. Chile.

2. Bioquímica. Magíster en Microbiología. Centro de Investigación de Biología y Regeneración Oral (CIBRO). Facultad de Odontología, Universidad de los Andes. Chile.

3. Bioquímico. Doctor en Inmunología. Investigador y Docente, Laboratorio Inmunología. Facultad de Medicina, Universidad de los Andes. Chile.

4. Cirujano Dentista. Especialista en Periodoncia. Área de Periodoncia. Docente, Facultad de Odontología, Universidad de los Andes. Chile. 
rechazo por el sistema inmune del individuo receptor y frecuentemente presentan un escaso o nulo potencial regenerativo ${ }^{(4,5,6)}$. Debido a las complicaciones que presentan y al éxito limitado de estos procedimientos, existe la necesidad de buscar nuevas alternativas terapéuticas con el fin de obtener resultados regenerativos eficientes a través del uso de mediadores biológicos e ingeniería tisular ${ }^{(5)}$. La ingeniería tisular representa una nueva línea de investigación emergente, que asiste y acelera el proceso de regeneración y reparación de los tejidos dañados en base a la potencia innata que posee cada individuo en su reparación ${ }^{(7)}$. El sustento biológico, es la utilización de células madres frescas, con su posterior expansión, diferenciación y modificación genética para la expresión de factores de crecimiento claves ${ }^{(8)}$.En relación a lo anterior, diversos estudios han demostrado que células madres mesenquimales pueden ser obtenidas a partir de diferentes tejidos humanos ${ }^{(9)}$, tales como: médula ósea ${ }^{(10,11)}$, tejido adiposo(12), cordón umbilical ${ }^{(13,14)}$, placenta( ${ }^{(15,16)}$ y piel(17) e incluso a partir de tejido conectivo gingival, como to ha demostrado nuestro grupo de investigación ${ }^{(18)}$. Estas células presentarían un gran potencial de proliferación ${ }^{(8)}$, lo que permitiría una reparación de alta calidad, regenerando las estructuras perdidas en cuanto a función y arquitectura, devolviendo ad integrum todos los tejidos dañados, como el hueso alveolar, tejido conectivo de inserción y distintos tipos de mucosa oral $^{(4)}$. Con el objetivo de regenerar los tejidos periodontales, se están investigando distintos biomateriales en los cuales puedan proliferar las células madres viables, y ser transportadas hacia un sitio en el cual se mantengan sin diseminarse y logren la regeneración de los defectos periodontales, gracias a la vascularización de la zona ${ }^{(19)}$.

Uno de los materiales en estudio es el quitosano, un polímero biodegradable y natural proveniente de la quitina, componente natural de la concha de crustáceos ${ }^{(20,21)}$. Es un biomaterial, que ha demostrado ser biocompatible y que no genera una reacción inflamatoria( ${ }^{(20)}$, convirtiéndose así en una herramienta útil para la ingenieria tisular. El objetivo del presente estudio experimental in vitro fue determinar la utilidad de la matriz de quitosano como vehículo de transporte de células madres de origen gingival con el fin de ser utilizadas para la regeneración de tejido óseo.

\section{MATERIAL Y MÉTODO}

\section{Obtención de Tejido Gingival}

La toma de muestra gingival se realizó en las dependencias del Centro de Salud de la Universidad de los Andes en San Bernardo para su posterior cultivo en el Centro de Biología y Regeneración Oral (CIBRO) de la Facultad de Odontología de la Universidad de los Andes. Las muestras de tejido gingival fueron obtenidas de mucosa oral a nivel distal del segundo molar superior de pacientes sanos voluntarios, previa firma de un consentimiento informado y aprobación del comité de ética de la Universidad de los Andes. Los pacientes recibieron anestesia local, previo cepillado de dientes y enjuague con colutorio de clorhexidina al $0.12 \%$, para luego ser extraído un trozo de tejido de aproximadamente $1 \times 1 \times 2 \mathrm{~mm}$ mediante técnica atraumática, con la utilización de bisturí estéril №12 y 15 y sutura simple.

Una vez obtenido el tejido gingival, se removió el epitelio en forma quirúrgica con hoja de bisturí estéril número $15 \mathrm{c}$, para luego ser depositado en un recipiente de $5 \mathrm{ml}$ con $2 \mathrm{ml}$ de medio de cultivo completo estéril compuesto por: " $\alpha$-MEM" mezclado con antibiótico Penicilina/ Estreptomicina (GIBCO, Invitrogen) y suero fetal bovino al $10 \%{ }^{(22)}$. Luego, la muestra de tejido gingival fue trasladada inmediatamente al Laboratorio para su procesamiento.

\section{Cultivo Celular y Obtención de Células Madres}

Una vez en el laboratorio, el tejido fue procesado de acuerdo a protocolos previamente establecidos en nuestro laboratorio para la obtención de MSCs ${ }^{(18)}$. Para ello, la muestra fue lavada 7 veces en tubos de $15 \mathrm{ml}$ con $5 \mathrm{ml}$ de solución salina fosfatada buffer (PBS) $1 \mathrm{X}+$ antibiótico (Penicilina y Estreptomicina).

Posteriormente, el explante fue cultivado en una placa de cultivo celular con $3 \mathrm{ml}$ de medio completo e incubado a $37^{\circ} \mathrm{C}$ con aire humidificado y $5 \%$ de $\mathrm{CO}_{2}$. El explante fue retirado de la placa una vez observado el crecimiento celular. El medio de cultivo fue renovado cada 3-4 días. La placa sembrada fue incubada hasta que se observó un $80 \%$ de confluencia celular. Luego las células fueron lavadas con PBS $1 \mathrm{X}$ y se sometieron a un proceso de separación de ellas del plástico con $1 \mathrm{ml}$ de tripsina $1 \mathrm{X}$ (Triple Sec GIBCO) durante 4 minutos. Una vez comprobada la separación celular en el microscopio óptico, se agregó $1 \mathrm{ml}$ de medio de cultivo completo y las células fueron colectadas en un tubo de 15 $\mathrm{ml}$ para luego ser centrifugadas durante 7 minutos a $1700 \mathrm{rpm}$. Una vez centrifugadas, se procedió a realizar el conteo y viabilidad celular en cámara de Neubauer. Una vez contadas las células, se cultivaron en un frasco de cultivo de mayor superficie $\left(25 \mathrm{~mm}^{2}\right)$ para permitir su proliferación, con medio de cultivo completo a una densidad de 10.000 $\mathrm{cel} / \mathrm{cm}^{2}$ (Pasaje 0). Se repitió el procedimiento de tripsinización y cultivo hasta llegar al pasaje 4. Con el fin de corroborar la presencia de células madres mesenquimales en el cultivo, estas fueron evaluadas de acuerdo a los criterios internacionales establecidos por "The International Society for Cellular Therapy Position Statement" los cuales son: a) presencia de morfología fibroblastoide, b) adherencia al plástico, c) diferenciación hacia tejido osteogénico, condrogénico y adipogénico y d) presencia de los marcadores CD73, CD90 y CD105 y ausencia para CD34 y CD45 $5^{(23)}$.

\section{Caracterización Inmunofenotípica}

La caracterización de las MSCs derivadas de tejido gingival en pasaje 4 fue realizada mediante citometría de flujo utilizando el siguiente panel de anticuerpos conjugados con fluoresceinisothiocyanate(FITC), phycoerytrin-(PE) o peridinin chlorophyllprotein(PerCP): antiCD34 (BeckmannCoulter),anti-CD45 (Beckmann Coulter), anti-CD73 (BDPharmingen), anti-CD90 (BDPharmingen) y anti-CD105 (Caltag) ${ }^{(23)}$. La adquisición y análisis de las muestras fue realizada utilizando un citómetro de flujo marca Coulter Epics-XL (Coulter Corporation, Florida, USA).

\section{Ensayos de Diferenciación}

Las células gingivales mesenquimales en pasaje 4 y con una confluencia del $80 \%$ fueron sembradas en 3 placas diferentes, modificando los medios de cultivo con reactivos que estimularan la diferenciación adipogénica, osteogénica y condrogénica de las células mesenquimales. Durante la diferenciación se realizó cambio de medio fresco de diferenciación cada 4 días. La duración del proceso varió según el medio de diferenciación utilizado.

a) Diferenciación Osteogénica: Se sembraron células en pasaje 4 en una densidad de $35.000 \mathrm{cel} / \mathrm{cm}^{2}$ en placas de 4 . Se incubó en la estufa a $37^{\circ} \mathrm{C}$ con $5 \% \mathrm{CO}_{2}$ toda la noche. Al día siguiente, se observaron las células al microscopio óptico. Al alcanzar el $100 \%$ de confluencia, (aproximadamente el segundo día) se agregó $500 \mu \mathrm{l}$ de medio de diferenciación con ( $\alpha$ MEM, SFB 10\%, Penicilina y Estreptomicina al 1\%), dexametasona $(0.1 \mu \mathrm{M})$, B-Glicerofosfato $(10 \mathrm{Mm})$, ascorbato-2 fosfato $(50 \mu \mathrm{g} / \mathrm{ml})$. Este último se agregó día por medio durante todo el proceso de diferenciación. Se mantuvieron incubadas en estufa a $37^{\circ} \mathrm{C}$ con $5 \%$ de $\mathrm{CO}_{2}$ durante todo el proceso, y se realizó cambio de medio cada 4 días. Cuando se observaron cúmulos de minerales y cristales birrefringentes al microscopio (al cabo de 4 semanas), se realizó la tinción Alizarin Red. Para ello, se preparó una solución de Alizarin Red $40 \mathrm{mM}$ en $\mathrm{NaH}^{2} \mathrm{PO}^{4}$ $0.1 \mathrm{M} \mathrm{pH}$ 4.3. Las células en las placas fueron lavadas 2 veces con 0.25 $\mathrm{mL} / \mathrm{cm}^{2}$ de PBS y fijadas con $0.25 \mathrm{~mL} / \mathrm{cm}^{2}$ de etanol $70 \%(\mathrm{v} / \mathrm{v})$ por 30 minutos a temperatura ambiente. Luego las células fueron lavadas 2 veces con PBS, agregándoseles $0.25 \mathrm{~mL} / \mathrm{cm}^{2}$ de Alizarin Red $40 \mathrm{mM}$ que se incubó por 10 minutos a temperatura ambiente. Las células en las placas fueron nuevamente lavadas 2 veces con PBS y finalmente se lavaron 5 veces con agua bidestilada. Se observó al microscopio óptico, y se tomaron fotografías de registro.

b) Diferenciación Condrogénica: Se sembraron células en una densidad de $30.000 \mathrm{cel} / 10 \mu \mathrm{l}$ en forma de microgota por pocillo en placas de 4 . Esto se llevó a cabo mediante micromasas, que se incubaron por una hora y media para luego agregarles el medio de diferenciación que incluía: (aMEM, SFB10\%, Penicilina y Estreptomicina al 1\%), Dexametasona $(0.1 \mu \mathrm{M})$, Insulina $(5 \mu \mathrm{g} / \mathrm{ml})$, TGF- $\beta 1(10 \mathrm{ng} / \mathrm{ml})$, ascorbato-2-fosfato $(50$ $\mu \mathrm{g} / \mathrm{ml}$ ). Estos dos últimos se agregaron día por medio durante todo el proceso de diferenciación. Se realizaron dos pruebas de diferenciación con sus respectivos controles negativos, los cuales sólo contenían 30.000 cel/10 $\mu \mathrm{l}$ más $500 \mu \mathrm{l}$ de medio completo ( $\alpha$ MEM, SFB10\%, Penicilina y Estreptomicina al 1\%), el que se cambió cada 4 días. Se mantuvieron incubadas en estufa a $37^{\circ} \mathrm{C}$ con $5 \%$ de $\mathrm{CO}_{2}$ durante todo el proceso, y se realizó cambio de medio cada 4 días. Pasado 2 semanas, se verificó que se hayan formado micromasas, para proceder a la tinción y comprobar la diferenciación hacia condrocito. Cuando se obtuvo micromasas que mostraran cúmulo celular, estas fueron teñidas mediante Safranina $O$, 
preparando una solución de safranina $\mathrm{O}$ al $0.1 \% \mathrm{p} / \mathrm{v}$. Las células fueron lavadas $1 \mathrm{vez}$ con PBS $1 \mathrm{X}$ y luego fijadas con $0.15 \mathrm{ml} / \mathrm{cm}^{2}$ de etanol al $70 \%$ v/v por 10 minutos. Se volvieron a lavar con PBS para luego agregar $0.15 \mathrm{ml} / \mathrm{cm}^{2}$ de safranina. Se esperó 5 minutos a temperatura ambiente y se volvió a lavar con $0.15 \mathrm{ml} / \mathrm{cm}^{2}$ de agua destilada. Posteriormente se eliminó el agua destilada y se lavó 5 veces con $0.15 \mathrm{ml} / \mathrm{cm}^{2}$ de etanol absoluto (100\%). Las células fueron observadas al microscopio de luz invertido con contraste de fase y fueron fotografiadas.

c) Diferenciación Adipogénica: Se sembraron células en una densidad de $25.000 \mathrm{cel} / \mathrm{cm}^{2}$ por pocillo en placas de 4 pocillos. Se incubó en la estufa a $37^{\circ} \mathrm{C}$ con $5 \% \mathrm{CO}_{2}$ durante un día. Al día siguiente, se observaron las células al microscopio óptico. Al alcanzar el $100 \%$ de confluencia (aproximadamente el segundo día), se agregó $500 \mu \mathrm{l}$ de medio de diferenciación con: ( $\alpha$ MEM, SFB 10\%, Penicilina y Estreptomicina al $1 \%)$, Dexametasona $(0.1 \mu \mathrm{M})$, Insulina $(10 \mu \mathrm{g} / \mathrm{ml})$, Indometacina $(0.02$ $\mathrm{mg} / \mathrm{ml}$ ). Se realizaron dos pruebas de diferenciación con sus respectivos controles negativos, los cuales sólo contenían $25.000 \mathrm{cel} / \mathrm{cm}^{2}$ más 500 $\mu \mathrm{l}$ de medio completo ( $\alpha$ MEM, SFB $10 \%$, Penicilina y Estreptomicina al $1 \%$ ), el que se cambió cada 4 días. Se mantuvieron incubadas en estufa a $37^{\circ} \mathrm{C}$ con $5 \%$ de $\mathrm{CO}_{2}$ durante todo el proceso, y se realizó cambio de medio de diferenciación cada 4 días. Pasado 4 semanas se marcó con Oil Red para comprobar la diferenciación hacia adipocito. Se preparó una solución de isopropanol $60 \% \mathrm{v} / \mathrm{v}$ a la que se agregó Oil Red $\mathrm{O}$ hasta generar una solución saturada. Luego se entibió por 20 minutos a $37^{\circ} \mathrm{C}$ y se filtró por un filtro de poros de $0.2 \mu \mathrm{m}$ para eliminar el exceso de cristales de Oil Red O. Las células en las placas fueron lavadas 2 veces con PBS. Luego se agregó Oil Red $O$ y se incubó por 1 hora a temperatura ambiente. A continuación, se lavó 2 veces con PBS y se observaron y fotografiaron las células que presentaban gotas de grasa teñidas de color rojo al interior de ellas.

\section{Análisis de la Matriz de Quitosano}

a. Para el análisis de las partículas de quitosano al microscopio óptico, se procedió a cortar con un bisturí estéril una lámina de quitosano de $25 \mathrm{~mm} \times 75 \mathrm{~mm}$ (Hem Con®), para dejar una delgada lámina semitransparente. Luego, bajo microscopía óptica, se tomaron fotografías digitales de registro.

b. Se utilizó una lámina de quitosano (HemCon®) de $25 \mathrm{~mm} \times 75$ $\mathrm{mm}$, la cual se pesó y se colocó $0.1 \mathrm{gr}$ en una placa de cultivo con $3 \mathrm{ml}$ de medio completo para evaluar su comportamiento en medio líquido, ya que el cultivo celular así lo requiere. Al cabo de 24 horas incubada a $37^{\circ} \mathrm{C}$ y $5 \%$ $\mathrm{CO}_{2}$, se observó al microscopio de luz y se tomaron fotografías de registro.

\section{Cultivo de MSCs en Presencia de Quitosano}

El quitosano se dejó disolver en una placa de cultivo con 3 $\mathrm{ml}$ de medio completo y se dejó por 24 horas a $37^{\circ} \mathrm{C}$ y $5 \%$ de $\mathrm{CO}_{2}$. Al día siguiente, se verificó la disolución del material y se calculó mediante diluciones la cantidad de medio necesario a sacar para obtener los siguientes porcentajes de quitosano: $2 \%(p / v), 1.5 \%(p / v), 1 \%(p / v)$, $0.75 \%(p / v), 0.5 \%(p / v), 0.25 \%(p / v), 0.2 \%(p / v), 0.1 \%(p / v)$ y $0.05 \%(p / v)$. Luego se agregó a cada pocillo $250.000 \mathrm{cel} / \mathrm{cm}^{2}$ en pasaje 4 y se agregó medio fresco hasta completar $500 \mu$ finales. Se re-suspendió todo de tal forma que se mezclase el quitosano y las células formando una solución homogénea. Se realizó paralelamente un control el cual contenía 250.000 $\mathrm{cel} / \mathrm{cm}^{2}$ más $500 \mu \mathrm{l}$ de medio completo. Se incubó a $37^{\circ} \mathrm{C}$ y $5 \%$ de $\mathrm{CO}_{2}$. Se tomaron fotografías bajo microscopía óptica al día 1, 3 y 7 .

Con el fin de evaluar la densidad celular, las células madres mesenquimales se tiñeron con cristal violeta y se cuantificó la absorbancia mediante un lector de ELISA a $510 \mathrm{~nm}$. En una placa de 96 pocillos se realizó en paralelo el mismo experimento con concentraciones de $1 \%$ $(\mathrm{p} / \mathrm{v}), 0.5 \%(\mathrm{p} / \mathrm{v}), 0.25 \%(\mathrm{p} / \mathrm{v})$ y $0.15 \%(\mathrm{p} / \mathrm{v})$ de quitosano con 35.000 $\mathrm{cel} / \mathrm{cm}^{2}$ con sus controles respectivos. Al cabo de 4 días se cuantificó la densidad celular presente en los pocillos de la placa de 96 pocillos mediante tinción con cristal violeta al $0.1 \%$, en un lector de ELISA.

\section{RESULTADOS}

\section{Cultivo Celular}

Una vez iniciado el cultivo del explante, este fue observado diariamente bajo microsocopia óptica para evaluar la morfología fibroblastoide y su adherencia a la superficie plástica de las células obtenidas. A los nueve días de cultivo se observó la presencia de células madres mesenquimales con morfología fibroblastide típica. A los 15 días las MSCs alcanzaron un $80 \%$ de confluencia celular demostrando su capacidad de proliferación como lo muestran las Figuras 1A y 1B.

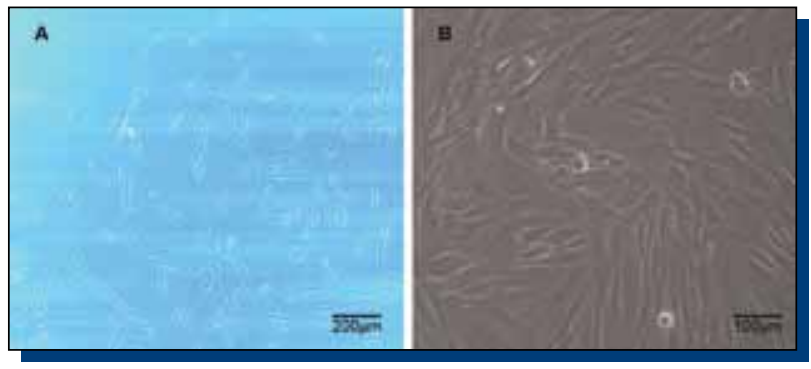

Figura 1A. Células explante con forma fibroblastoides adherentes al plástico luego de 9 días de cultivo. Microscopio óptico. Magnificación 10X. Figura 1B. Células explante trozado alcanzando una confluencia del $80 \%$, día 15 , previo a tripsinización. Microscopioóptico, magnificación 20X.

\section{Ensayos de Diferenciación}

Los ensayos de diferenciación demostraron que las células obtenidas fueron capaces de diferenciarse a linaje osteogénico, condrogénico y adipogénico demostrando así la plasticidad celular que poseen las MSCs derivadas de tejido gingival (Figuras $2 \mathrm{~A}, 2 \mathrm{~B}$ y $2 \mathrm{C}$, respectivamente)

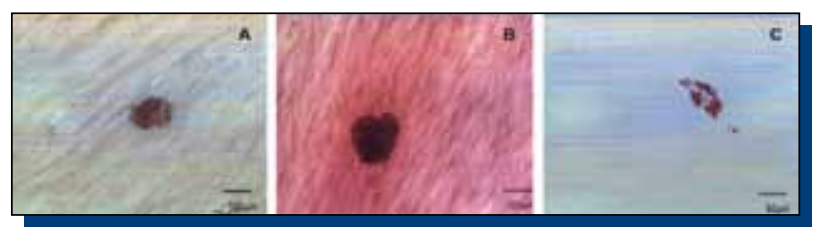

Figura 2A. Diferenciación osteogénica, foco de diferenciación teñido de rojo con Alizarin Red. Microscopía óptica con contraste de fase, magnificación 20X. Figura 2B. Diferenciación condrogénica, micromasa de células cartilaginosa teñida de rojo con Safranina O. Microscopía óptica con contraste de fase, magnificación $20 \mathrm{X}$. Figura 2C. Diferenciación adipogénica, presencia de vesículas grasas al interior de una células teñidas de rojo con Oil Red. Microscopía con contraste de fase, magnificación $40 \mathrm{X}$.

\section{Caracterización Inmunofenotípica}

Las MSCs fueron analizadas mediante citometría de flujo, demostrando aproximadamente un $99 \%$ de positividad para los marcadores CD73, CD90 y CD105 y menos de un 3\% de negatividad para los marcadores CD34 y CD45, disponiendo asi para los experimentos con quitosano de MSCs con una pureza de un $97 \%$.

\section{Análisis Microscópico del Quitosano}

Luego de cortar una delgada lámina de quitosano, fue posible observar la arquitectura de la matriz de quitosano bajo el microscopio óptico, pesquisando la presencia de un gran ramificado que dificulta el paso de la luz.

Al pesar 0.1 grs de la presentación de quitosano y dejarla 24 horas suspendida en $2 \mathrm{ml}$ de medio completo, se observó que ésta se disuelve formando un gel líquido con presencia de burbujas, que se pudo ver tanto al ojo humano como en microscopía de luz.

En cuanto a las curvas de crecimiento en relación a la concentración de quitosano, se observó que a medida que se aumenta la concentracion de quitosano (de $0.25 \%(\mathrm{p} / \mathrm{v})$ ) de quitosano hacia arriba), las células adquieren una forma más ovalada comparada con las celulas del control, perdiendo su morfologia fibroblastoide. Por otro lado, la proliferacion celular se ve disminuida, alcanzando una confluencia celular del $90 \%$ en concentraciones iguales o superiores a $0.75 \%(\mathrm{p} / \mathrm{v})$ de material, a diferencia del control y las otras concentraciones inferiores que alcanzaron un $100 \%$ de confluencia celular.

Ensayo de densidad celular con cristal violeta en relación a la concentración de quitosano. 


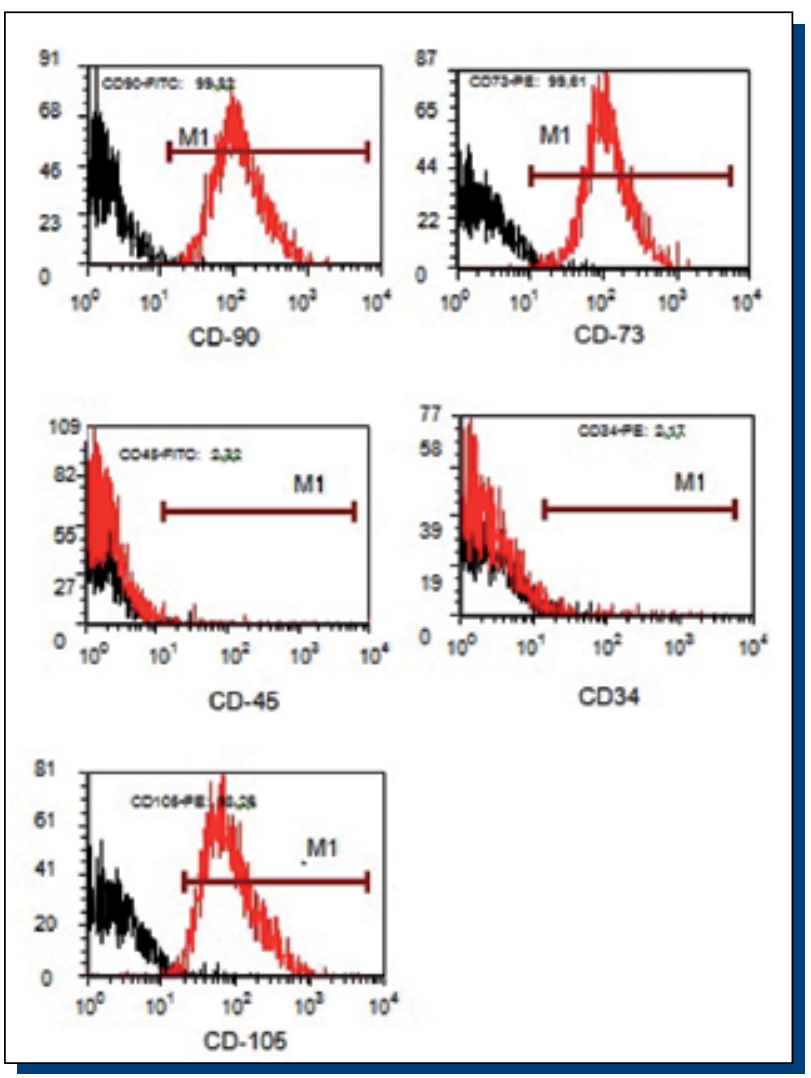

Figura 3. Caracterización inmunofenotípica.

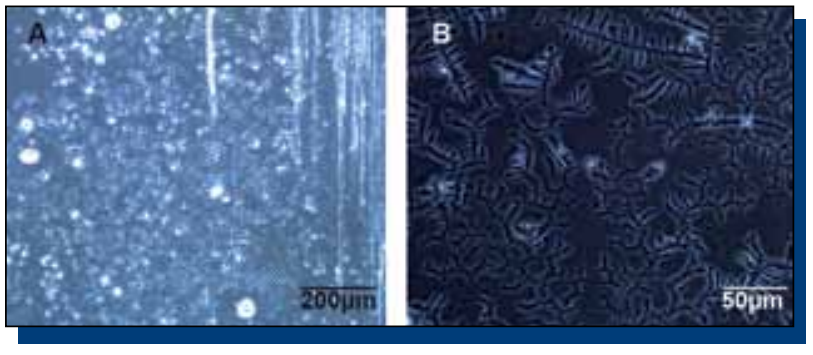

Figura 4A. Estructura de quitosano al microscopio óptico, magnificación10X. Figura 4B. Estructura de quitosano al microscopio óptico, magnificación 40X

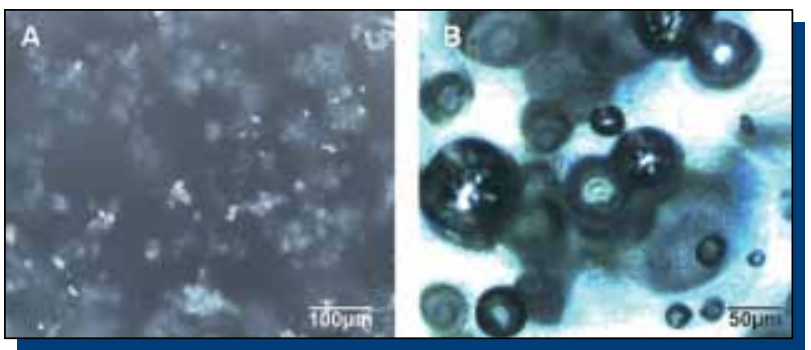

Figura 5A. Quitosano tras 24 horas sumergido en medio completo. Microscopía óptica, magnificación 20X. Figura 5B. Quitosano tras 24 horas sumergido en medio completo. Microscopía óptica, magnificación 40X.

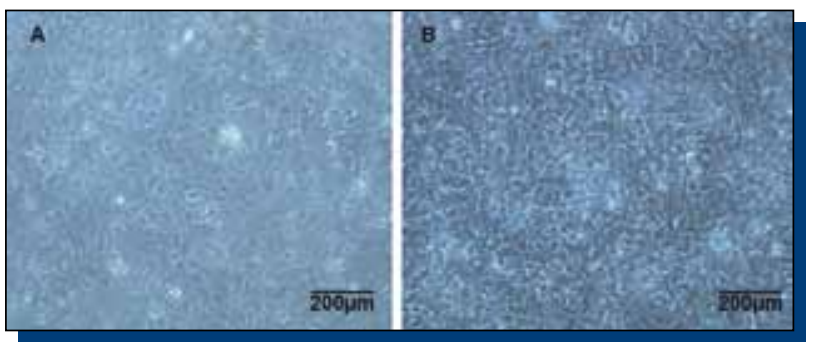

Figura 6A. Curva de crecimiento $2 \%$ (p/v) de quitosano con $250.000 \mathrm{cel} / \mathrm{cm}^{2}$. Confluencia celular $100 \%$. Microscopía óptica, magnificación 10X. Figura 6B. Curva de crecimiento $0.25 \%(\mathrm{p} / \mathrm{v})$ de quitosano con 250.000 cel/cm². Confluencia celular 100\%. Microscopía óptica, magnificación 10X.

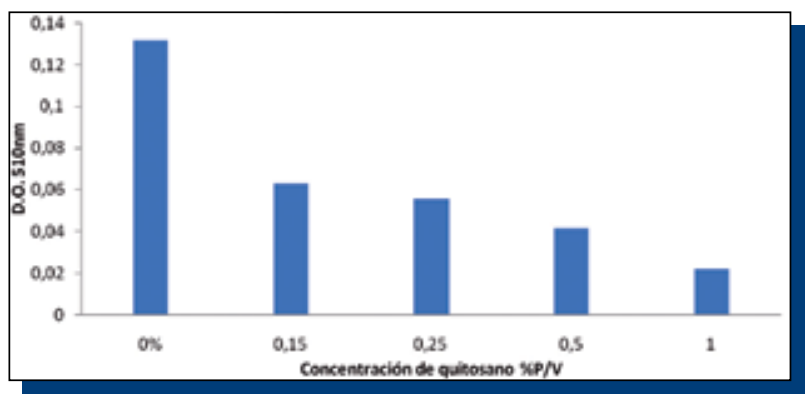

Gráfico 1. Unidades de densidad óptica (D.O.) a $510 \mathrm{~nm}$ v/s concentración \% (p/v) de quitosano en cultivos con $70.000 \mathrm{cel} / \mathrm{cm}^{2}$.

\section{DISCUSIÓN}

La demanda por encontrar nuevas terapias para el tratamiento de defectos óseos es altísima, existiendo así múltiples técnicas capaces de entregar una regeneración la cual no siempre resulta ser exitosa como es el caso de los injertos, que presentan morbilidad del sitio donante y rechazo inmunológico en algunos casos. La ingeniería tisular es una disciplina innovadora capaz de entregar una regeneración de mejor calidad con nula reacción de rechazo y sin o mínima morbilidad del sitio donante dependiendo si las células obtenidas son de banco o del propio paciente. Esta estrategia se basa en combinar células con una matriz 3D más factores de crecimiento ${ }^{(24)}$. Diversos estudios han logrado aislar y diferenciar MSCs a partir de diferentes tejidos en los cuales se incluye el ligamento periodontal ${ }^{(25,26,27)}$. En el año 2010 se publicó un estudio de Mitrano et al, en el cual en el laboratorio de inmunología de la Universidad de los Andes, se lograron aislar y caracterizar células madres mesenquimales provenientes del tejido gingival ${ }^{(18)}$.En el presente trabajo de investigación se logró aislar células madres mesenquimales a partir de tejido conjuntivo gingival, lo que pudimos comprobar mediante los parámetros propuestos por "The International Society for Cellular Therapy Position Statement", que incluyen: Morfología fibroblastoide, Adherencia al plástico, Diferenciación al menos a tres estirpes celulares, Caracterización inmunofenotípica de la $\mathrm{MSCs}^{(23)}$.

En todos nuestros cultivos celulares se observó a partir del noveno día la presencia de células de morfología fibroblastoide adherentes a la placa con gran potencial de autorrenovación, las que al encontrarse en pasaje 4 de cultivo fueron diferenciadas hacia linaje osteogénico, condrogénico y adipogénico en presencia de medios de diferenciación específicos, quedando demostrada su plasticidad. En cuanto a la caracterización inmunofenotípica de las células en estudio, sobre un $95 \%$ de la población expresó los marcadores CD73,CD90 y CD105 al ser analizadas por citometría de flujo siendo negativas para CD34 y CD45 cumpliendo lo establecido por Dominici et al, el año $2006^{(23)}$. Para que las células aisladas puedan ser llevadas al sitio en cuestión, es necesario un material que actúe como medio de transporte celular. Una matriz ideal debería ser absorbible y resistente a la reacción inflamatoria del huésped con el fin de mantener el espacio del defecto a regenerar y así para permitir la migración celular ${ }^{(28)}$. Estudios han demostrado que el quitosano, un polímero natural, presenta una excelente biocompatibilidad, no es citotóxico ni presenta inmunogenicidad siendo un buen candidato para la reparación de defectos óseos ${ }^{(24)}$. Es por esto que en nuestro trabajo elegimos estudiar el quitosano como material de transporte celular.

El análisis ultra estructural del quitosano evidenció que la lámina de quitosano se disolvió formando un gel en presencia de un medio completo lo que indicaría que el quitosano utilizado en este estudio no es apto para ser utilizado como matriz ya que pierde su solidez estructural en presencia de medio líquido siendo incapaz de ser utilizado como transporte celular, lo que se explica en un estudio de Costa-Pinto et al, donde se evaluaron los patrones de crecimiento y diferenciación osteogénica de MSCs provenientes de médula ósea humana sembradas en una matriz de quitosano con poliéster, debido a que indican que el quitosano presenta limitadas propiedades mecánicas, por lo que matrices producidas sólo de quitosano son más difíciles de optimizar para aplicaciones de tejido duro, requiriendo así combinarse con otro material(24)

Los resultados obtenidos en nuestro trabajo de investigación con la presentación comercial que se utilizó de quitosano, no son comparables a los resultados obtenidos por diferentes autores, ya que en 
los estudios analizados las membranas de quitosano fueron fabricadas por los propios investigadores, como en el estudio de Seol (2004), donde se fabricaron esponjas de quitosano observándose proliferación y diferenciación de células madres hacia linaje osteoblástico, sin embargo este estudio no describe las características del quitosano utilizado ni detalla de manera específica la forma de fabricación de las membranas ${ }^{(29)}$. En otros estudios analizados, el quitosano fue combinado con otro biomaterial, como en el estudio de Moreau y Xu (2009), donde se evaluó la proliferación y diferenciación hacia linaje osteogénico de MSCs en matrices compuestas de quitosano y fosfato de calcio ${ }^{(30)}$.

Al utilizar distintas disoluciones de quitosano en medio completo para realizar las curvas de crecimiento celular, se observó que la proliferación celular es inversamente proporcional a la concentración de quitosano, evidenciándose siempre mayor densidad celular y viabilidad en los pocillos control, lo que se comprobó mediante la absorbancia del cristal violeta en las lecturas de ELISA. Los resultados obtenidos de este experimento son similares a los resultados obtenidos por Maeng et al (2009), donde se fabricaron microcamas con distintas concentraciones de quitosano mediante electrospray, y se observó que el número de células adheridas disminuía a medida que se aumentaba la concentración de quitosano ${ }^{(31)}$.

Otro aspecto importante a considerar, es que a medida que la concentración de quitosano aumenta, el fenotipo celular se altera cambiando así su morfología fibroblastoide a una más redondeada lo que indicaría un cambio en la condición genética celular en presencia de grandes concentraciones de quitosano.

La búsqueda de matrices para el transporte celular en ingeniería tisular es una necesidad creciente. El quitosano ha sido propuesto como un adecuado medio en diversas publicaciones, sin embargo en nuestra investigación conforme al tipo de presentación comercial de quitosano empleada, a pesar de existir proliferación celular de MSCs proveniente de tejido gingival humano a determinadas concentraciones de quitosano, su capacidad de actuar como medio de transporte celular es deficiente puesto que se disgrega al contacto con medio líquido, requiriendo así combinarse con otro material para poder ser transportado.

\section{CONFLICTOS DE INTERÉS}

Los autores de la presente investigación declaran no presentar ningún tipo de conflicto de intereses en relación a la metodología de la investigación ni haber sido financiados por ninguna empresa privada.

\section{REFERENCIAS BIBLIOGRÁFICAS}

1. Lindhe J, Karring and Lang. Clinical periodontology and implantdentistry. 5ed Vol. 1. 2008, Inglaterra: Blackwell.

2. Zhang $X$ et al. A perspective: Engineering periosteum for structural bone graft healing. Clin Orthop Relat Res, 2008; 466(8): 1777-1787.

3. Finkemeier CG. Bone-grafting and bone-graft substitutes. J Bone Joint Surg Am, 2002; 84-A(3): 454-464.

4. Bartold PM, Shi S, Gronthos S. Stem cells and periodontal regeneration. Periodontol 2000, 2006; 40: 164-172.

5. Kao RT, Murakami S, Beirne OR. The use of biologic mediators and tissue engineering in dentistry. Periodontol 2000, 2009; 50: 127-153.

6 . Tsuang YH et al. In vitro cell behavior of osteoblasts on Pyrost bone substitute. Anat Rec, 1997; 247(2): 164-169.

7. Tabata Y. Biomaterial technology for tissue engineering applications. JR Soc Interface, 2009; 6 Suppl 3: S311-324.

8. Pountos I et al. Mesenchymal stem cell tissue engineering: Techniques for isolation, expansion and application. Injury, 2007; 38 Suppl 4: S23-33. 9. Sudo $\mathrm{K}$ et al. Mesenchymal progenitors able to differentiate into osteogenic, chondrogenic, and/or adipogenic cells in vitro are present in most primary fibroblast-like cell populations. Stem Cells, 2007; 25(7): 16101617.

10. Pittenger MF et al. Multilineage potential of adult human mesenchymal stem cells. Science, 1999; 284(5411): 143-147.

11. Colter DC, Sekiya I, Prockop DJ. Identification of a subpopulation of rapidly self-renewing and multipotential adult stem cells in colonies of 138 human marrow stromal cells. Proc Natl Acad Sci USA, 2001; 98(14): 7841-7845.

12. Zuk PA et al. Human adipose tissue is a source of multipotent stemcells. Mol Biol Cell, 2002; 13(12): 4279-4295.

13. Hou $L$ et al. Induction of umbilical cord blood mesenchymal stem cellsinto neuron-like cells in vitro. Int J Hematol, 2003; 78(3): 256-261. 14. Lee MW et al. Isolation of mesenchymal stem cells fromcryopreserved human umbilical cord blood. Int J Hematol, 2005; 81(2): 126-130.

15. Fukuchi Y et al. Human placenta-derived cells have mesenchymalstem/ progenitor cell potential. Stem Cells, 2004; 22(5): 649-658.

16. Anker PS et al. Isolation of mesenchymal stem cells of fetal ormaternal origin from human placenta. Stem Cells, 2004; 22(7): 1338-1345.

17. Toma JG et al. Isolation and characterization of multipotent skinderived precursors from human skin. Stem Cells, 2005; 23(6): 727-737.
18. Mitrano Tl et al. Culture and characterization of mesenchymal stemcells from human gingival tissue. J Periodontol, 2010; 81(6): 917-925.

19. Slavkin HC, Bartold PM. Challenges and potential in tissue engineering. Periodontol 2000, 2006; 41: 9-15.

20 . Shin SY et al. Biological evaluation of chitosan nanofiber membranefor guided bone regeneration. J Periodontol, 2005; 76(10): 1778-1784.

21. Lee $Y M$ et al. Tissue engineered bone formation usingchitosan/ tricalcium phosphate sponges. J Periodontol, 2000; 71(3): 410-417.

22. Seo BM et al. Investigation of multipotent postnatal stem cells fromhuman periodontal ligament. Lancet, 2004; 364(9429): 149-155.

23. Dominici $M$ et al. Minimal criteria for defining multipotent mesenchymalstromal cells. The International Society for Cellular Therapy positionstatement. Cytotherapy, 2006; 8(4): 315-317.

24. Costa-Pinto AR et al. Osteogenic differentiation of human bonemarrow mesenchymal stem cells seeded on melt based chitosanscaffolds for bone tissue engineering applications. Biomacromolecules, 2009; 10(8): 20672073.

25. Lin NH, Gronthos S, Mark Bartold P. Stem cells and futureperiodontal regeneration. Periodontol 2000, 2009; 51: 239-251.

26. Morsczeck $C$ et al. Somatic stem cells for regenerative dentistry. Clin Oral Investig, 2008; 12(2): 113-118.

27. Baksh D, Song L, Tuan RS. Adult mesenchymal stem cells: Characterization, differentiation, and application in cell and gene therapy. J Cell Mol Med, 2004; 8(3): 301-316.

28. Jung UW et al. Effects of a chitosan membrane coated with polylacticand polyglycolic acid on bone regeneration in a rat calvarial defect. Biomed Mater, 2007; 2(3): S101-105.

29. Seol YJ et al. Chitosan sponges as tissue engineering scaffolds for bone formation. Biotechnol Lett, 2004; 26(13): 1037-1041.

30. Moreau JL, $\mathrm{Xu} \mathrm{HH}$. Mesenchymal stem cell proliferation anddifferentiation on an injectable calcium phosphate-chitosan compositescaffold. Biomaterials, 2009; 30(14): 2675-2682.

31. Maeng $\mathrm{YJ}$ et al. Culture of human mesenchymal stem cells usingelectrosprayed porous chitosan microbeads. J Biomed Mater Res A, 2010; 92(3): 869-876. 